\title{
Corrigendum
}

\section{Corrigendum to "Explosion Resistance of Three-Dimensional Mesoscopic Model of Complex Closed-Cell Aluminum Foam Sandwich Structure Based on Random Generation Algorithm"}

\author{
Zhen Wang, Wen Bin Gu ${ }^{D}$, Xing Bo Xie, Qi Yuan, Yu Tian Chen, and Tao Jiang \\ Army Engineering University of PLA, Nanjing 210007, China \\ Correspondence should be addressed to Wen Bin Gu; 1120122090@bit.edu.cn
}

Received 28 October 2020; Accepted 28 October 2020; Published 21 November 2020

Copyright (c) 2020 Zhen Wang et al. This is an open access article distributed under the Creative Commons Attribution License, which permits unrestricted use, distribution, and reproduction in any medium, provided the original work is properly cited.

In the article titled "Explosion Resistance of Three-Dimensional Mesoscopic Model of Complex Closed-Cell Aluminum Foam Sandwich Structure Based on Random Generation Algorithm" [1], there was an error in
Figures 1(c) and 2 due to the incorrect version of the code being used. The authors confirm that this does not affect the results and conclusions of the article, and the corrected Figures 1(c) and 2 are as follows:

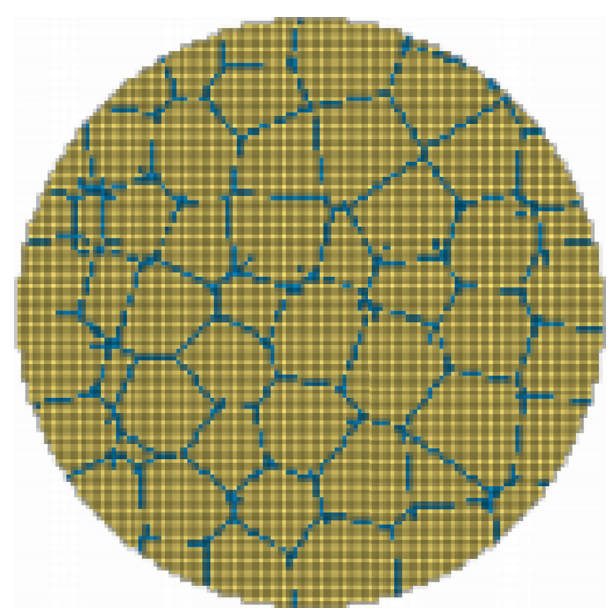

FiguRE 1: The real structure and numerical simulation structure of aluminum foam. 


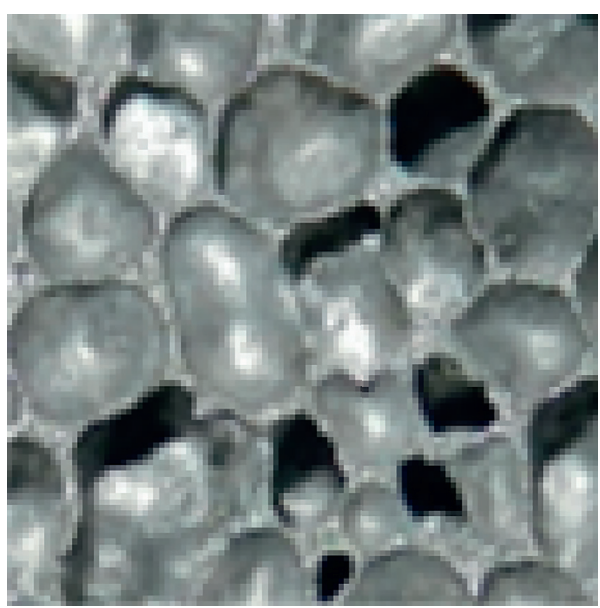

(a)

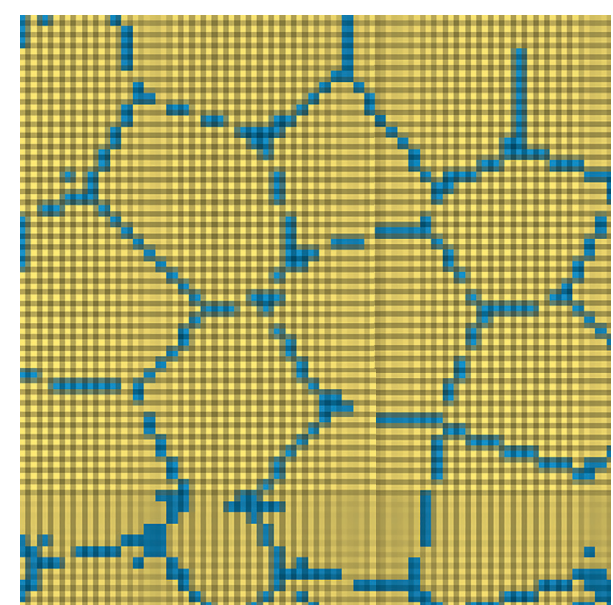

(b)

Figure 2: Comparison of different sections of the model with the real structure.

\section{References}

[1] Z. Wang, W. B. Gu, X. B. Xie, Q. Yuan, Y. T. Chen, and T. Jiang, "Explosion resistance of three-dimensional mesoscopic model of complex closed-cell aluminum foam sandwich structure based on random generation algorithm," Complexity, vol. 2020, Article ID 8390798, 16 pages, 2020. 